\title{
Characterizing urban expansion of Korla City and its spatial-temporal patterns using remote sensing and GIS methods
}

\author{
Bumairiyemu MAIMAITI ${ }^{1,2,3,4}$, DING Jianli ${ }^{1,2^{*}}$, Zibibula SIMAYI ${ }^{1,2,4}$, Alimujiang KASIMU ${ }^{5}$ \\ ${ }^{1}$ College of Resource and Environment Sciences, Xinjiang University, Urumqi 830046, China; \\ ${ }^{2}$ Key Laboratory of Oasis Ecology, Xinjiang University, Urumqi 830046, China; \\ ${ }^{3}$ Key Laboratory of Wisdom City and Environment Modeling of Colleges and Universities, Xinjiang University, Urumqi \\ 830046, China; \\ ${ }^{4}$ School of Management, Xinjiang Agricultural University, Urumqi 830052, China; \\ ${ }^{5}$ School of Geographic Science and Tourism, Xinjiang Normal University, Urumqi 830054, China
}

\begin{abstract}
Cities provide spatial contexts for populations and economic activities. Determining the spatial-temporal patterns of urban expansion is of particular significance for regional sustainable development. To achieve a better understanding of the spatial-temporal patterns of urban expansion of Korla City, we explore the urban expansion characteristics of Korla City over the period 1995-2015 by employing Landsat TM/ETM+ images of 1995, 2000, 2005, 2010, and 2015. Urban land use types were classified using the supervised classification method in ENVI 4.5. Urban expansion indices, such as expansion area, expansion proportion, expansion speed, expansion intensity, compactness, and fractal dimension, were calculated. The spatial-temporal patterns and evolution process of the urban expansion (e.g., urban gravity center and its direction of movement) were then quantitatively analyzed. The results indicated that, over the past 25 years, the area and proportion of urban land increased substantially with an average annual growth rate of $15.18 \%$. Farmland and unused land were lost greatly due to the urban expansion. This result might be attributable to the rapid population growth and the dramatic economic development in this area. The city extended to the southeast, and the urban gravity center shifted to the southeast as well by about $2118 \mathrm{~m}$. The degree of urban compactness tended to decrease and the fractal dimension index tended to increase, indicating that the spatial pattern of Korla City was becoming loose, complex, and unstable. This study could provide a scientific reference for the studies on urban expansion of oasis cities in arid land.
\end{abstract}

Keywords: urban expansion; spatial-temporal changes; urban land; remote sensing and GIS; Korla City

Citation: Bumairiyemu MAIMAITI, DING Jianli, Zibibula SIMAYI, Alimujiang KASIMU. 2017. Characterizing urban expansion of Korla City and its spatial-temporal patterns using remote sensing and GIS methods. Journal of Arid Land, 9(3): 458-470. doi: 10.1007/s40333-017-0099-y

\section{Introduction}

Urban expansion is a phenomenon reflecting the demand for land caused by industrial growth and population increase (Mohurd, 1999; Qiao et al., 2016; Aimaiti et al., 2016). It is a result of urbanization, the process of people migrating from rural to urban areas (Liu et al., 2012; Sun et al., 2013; Liu et al., 2016). However, unplanned and poorly-planned urban expansion usually leads to inefficient use of land, loss of farmland, environmental pollution, and ecological degradation (Tan et al., 2005). China has experienced rapid urbanization since 1978, and the

${ }^{*}$ Corresponding author: DING Jianli (E-mail: watarid@xju.edu.cn)

Received 2016-08-14; revised 2017-03-17; accepted 2017-04-07

(C) Xinjiang Institute of Ecology and Geography, Chinese Academy of Sciences, Science Press and Springer-Verlag Berlin Heidelberg 2017 
urbanization rate reached 56.10\% in 2015 (NBSC, 2016). The rapid urban expansion caused dramatic changes in the landscapes and had substantial impacts on social, economic, and natural environment (Chen et al., 2009; Zhang et al., 2012; Wang et al., 2013; Nian et al., 2014; Yang et al., 2015).

Studies of urban expansion mainly focused on two aspects, the qualitative and quantitative measurement of urban spatial patterns, and the demarcation of urban spatial expansion. Frankhauser (1990) provided a series of analysis results and calculation methods based on the fractal dimension. Batty (1994) analyzed the spatial expansion pattern of urban areas and the structure of urban land use by employing fractal theory. Gradient analysis and landscape metrics were often adopted to quantify land spatial patterns (Collins and Woodcoch, 1996; Luck and Wu, 2002). Long et al. (2009) determined the urban growth boundary based on binding cellular automata, whereas Yang et al. (2010) noted a distinction between rigid and elastic growth boundaries. Numerous studies were performed in many large cities of China (Liu et al., 2002; Shi et al., 2009; Xiao and Tian, 2014; Zhao et al., 2015), including characterizing the spatial-temporal patterns, detecting the dynamics, and modeling urban land uses. A few studies also examined the urban expansion in the arid and semi-arid areas of northwestern China. For example, Kasimu et al. (2013) extracted the spatial-temporal characteristics of urban expansion of 16 oasis cities in Xinjiang using remote sensing (RS) and geographic information system (GIS) techniques. However, there is a lack of systematic, comprehensive, long term studies that examine the urban expansion of typical individual cities, particularly the oasis cities of southern Xinjiang.

Urban expansion studies often use methods and indices to analyze the intensity, speed, anisotropy, and spatial heterogeneity of expansion. These methods and indices include average patch area (Yu and $\mathrm{Ng}, 2007$ ), compactness index (Hagen-Zanker and Timmermans, 2008; Shi et al., 2015), gradient analysis (Vizzari, 2011), shape index (Kasimu and Aimaiti, 2012), fractal dimension (Nie et al., 2015), sprawl intensity (Boori et al., 2015; Mohammady and Delavar, 2016), spatial metrics (Aithal and Ramachandra, 2016; Debbage et al., 2016), and percentage of built-up area (Liu et al., 2017). However, these methods and indices are often difficult to apply to the oasis cities in the arid and semi-arid areas that are scattered in distribution and irregular in shapes. In that regard, RS images and GIS techniques can provide frequent and accurate land observation data to detect spatial changes and to assess urban expansion trends (Yeh and Li, 1999; Weng, 2001). In contrast to traditional statistical data, RS technology is objective and can offer real-time coverage at a lower cost for quantitatively analyzing the spatial-temporal patterns of urban expansion (Kasimu and Maimaitiming, 2012; Boori et al., 2015).

It is commonly known that economic development and urban expansion are mutually influenced and restricted. The year of 1990 was a historical turning point for the economic development of Korla City due to the Natural Gas Transmission Project from West to East originated here and the establishment of the Tarim Oilfield Company. This study aimed to reveal the spatial-temporal patterns of urban expansion in Korla City over the period 1990-2015 and to explore the driving forces of the urban expansion. The results can provide scientific supports for economic development and land use management for Korla City.

\section{Study area}

Korla City, the capital city of the Bayingolin Mongolian Autonomous Prefecture, Xinjiang Uygur Autonomous Region, China, is located in the hinterland of Euro-Asia continent $\left(41^{\circ} 10^{\prime} 48^{\prime \prime}-\right.$ $42^{\circ} 21^{\prime} 36^{\prime \prime} \mathrm{N}, 85^{\circ} 14^{\prime} 10^{\prime \prime}-86^{\circ} 34^{\prime} 21^{\prime \prime} \mathrm{E}$; $950 \mathrm{~m}$ a.s.1.; Fig. 1) and situated at the northeastern edge of the Tarim Basin. It is the largest city in southern Xinjiang and the second largest city in Xinjiang. It covers an area of $7.268 \times 10^{3} \mathrm{~km}^{2}$ and is an important political, economic, and cultural center. At the end of 2015 , the non-agricultural population $\left(0.36 \times 10^{6}\right)$ accounted for $65.06 \%$ of the total population $\left(0.56 \times 10^{6}\right)$; the GDP was $66.40 \times 10^{9}$ yuan, and the GDP per capita was $112 \times 10^{3}$ yuan; the secondary and tertiary industry outputs were $49.40 \times 10^{9}$ yuan and $13.00 \times 10^{9}$ yuan, accounting for $74.42 \%$ and $19.54 \%$ of total GDP, respectively.

In this study, we focused on the core urban built-up areas, where the public facilities and 
municipal utilities are available and convenient, and the buildings are relatively contiguous. The core urban built-up areas include all artificially constructed elements such as roads, factories, residential areas, and parks with water and vegetation. According to this concept, we extracted the main functional area rather than the administrative area from the RS images (Fig. 1).

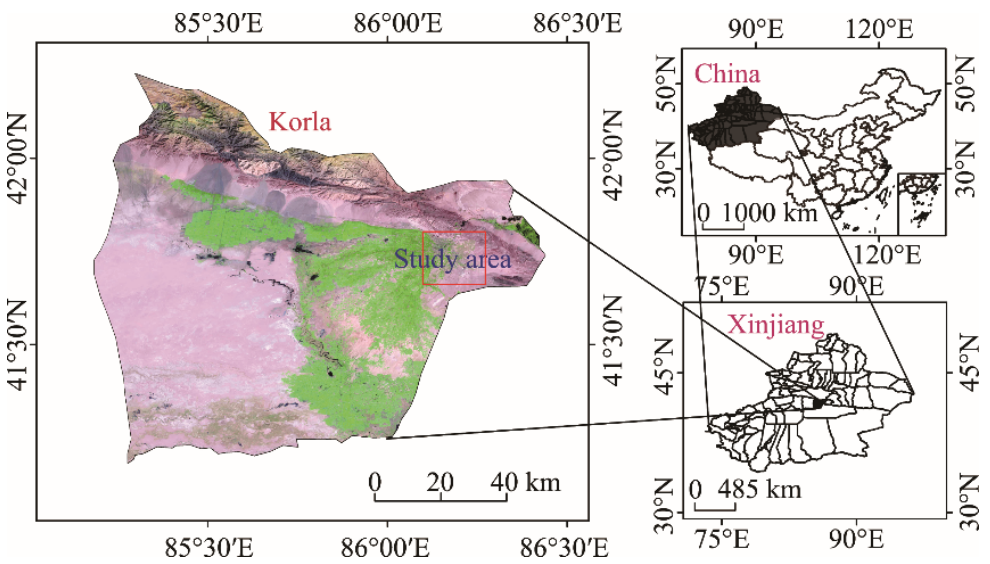

Fig. 1 Location of the study area

\section{Data and methods}

\subsection{Data sources}

Landsat TM/ETM+ images of 1990, 1995, 2000, 2005, 2010 and 2015 were obtained from the official website of the United States Geological Survey (https://www.usgs.gov) and the Geo-spatial Data Cloud of China (http://www.gscloud.cn). To ensure the clarity, we selected the images with cloud coverage percentage less than 10\% (Table 1). The socioeconomic data were obtained from the Xinjiang Statistical Yearbook (Statistics Bureau of Xinjiang Uygur Autonomous Region, 1991-2016) and from the Korla City government website (http://www.xjkel.gov.cn). Land use maps were provided by the Korla Land and Resource Bureau. We also performed two field surveys in 2010 and 2015, respectively.

The ENVI 4.5 was used for image processing and the ArcGIS 10.1 was used for mapping and spatial analysis. SPSS 19.0 and Microsoft Excel were used for statistical analysis.

Table 1 Remoting sensing (RS) data

\begin{tabular}{lcccccc}
\hline Parameter & Jul 1990 & Aug 1995 & Jul 2000 & Jul 2005 & Aug 2010 & Jul 2015 \\
\hline Sensor type & TM & TM & TM & ETM $^{+}$ & ETM $^{+}$ & OLI \\
Spatial resolution (m) & 30 & 30 & 30 & 30 & 30 & 30 \\
Bands for classification & 743 & 743 & 743 & 743 & 743 & 654 \\
Cloud coverage (\%) & $<10$ & $<10$ & $<10$ & $<10$ & $<10$ & $<10$ \\
\hline
\end{tabular}

\subsection{Image processing}

ENVI 4.5 was used to implement geometric corrections and atmospheric corrections to improve the accuracy of the original image data. Since the images of 2005 and 2010 included image strips, the gap fill method was applied to remove the "noise" information from the images.

According to the urban land resource classification system, which is promoted by the "National Resources \& Environment Survey and Dynamic Monitoring Using Remote Sensing" of Chinese Academy of Sciences, we classified the land use types in the urban built-up-area into 6 categories: urban land, farmland, woodland, water body, grassland, and unused land (Liu, 1997). During the in situ investigation, we found there was no obvious grassland within the built-up areas over the 25 -year study period. Thus, the category of grassland was ignored.

The maximum likelihood algorithm was applied to perform supervised classification. In the 
interpretation, the band composite used for visualization for 2015 images was band 4, 5 and 6 (shown in blue, green and red, respectively), whereas the composite of band 3, 4 and 7 (shown in blue, green and red, respectively) were used for the other years. The spectral differences among the different land use types were significant, and the land use types could be easily identified using these bands (Chen et al., 2009). To improve the accuracy, we selected at least 100 ground-truth pixels from each land use type, which were extracted based on field investigations of 2010 and 2015 and also on land use maps for the other periods. The classification results were compared against the high spatial resolution data (higher than $2.5 \mathrm{~m}$ ) in Google Earth and also with the land use maps from the other sources. Post classification method was applied to eliminate the influence of such problems as spectral dissimilarity of same land use classes and the spectral similarity of different land use classes. The classification accuracy was tested by human-computer interaction and was checked using the reference data collected from field investigations and land use maps. As can be seen from Table 2, both the overall accuracy and the Kappa coefficient values were high enough for the study period, indicating that the classification results were acceptable and ready for further analysis.

Table 2 Accuracy assessment of classification

\begin{tabular}{ccccccc}
\hline & 1990 & 1995 & 2000 & 2005 & 2010 & 2015 \\
\hline Kappa coefficient & 0.854 & 0.982 & 0.856 & 0.843 & 0.866 & 0.924 \\
Overall accuracy (\%) & 88.12 & 92.84 & 85.78 & 85.34 & 89.08 & 96.69 \\
\hline
\end{tabular}

\subsection{GIS spatial analysis}

We evaluated the urban spatial and temporal patterns using land use transfer matrix, urban gravity center, urban expansion indices, and urban spatial pattern indices. Land use transfer matrix can indicate the source of expanded urban land and the degree of contribution from different land use types to the expansion. The urban gravity center indicates the urban movement direction and can help to determine the expansion mode of the urban land to some extent. Urban expansion indices can quantitatively describe the urban expansion features. Urban spatial pattern indices can provide a system-level analysis to describe the forms and the process of urban expansion.

\subsubsection{Land use transfer matrix}

We used the land use transfer indices (Eq. 1) to evaluate the specific contribution of each land use type to urban land use. The matrix can quantitatively disclose the mutual conversion relationships among different land use types and can specifically and comprehensively describe the areas, structural characteristics and change trends for each land use type.

$$
L C C=C_{n} \times 10+C_{n+1} \text {. }
$$

Where, $L C C$ is the land cover change; $C_{n}$ and $C_{n+1}$ are the land use types before and after a set of changes, respectively; and $n$ is the study year ( $\mathrm{Li}$ et al., 2009).

\subsubsection{Urban gravity center}

The urban gravity center can describe the changes in the urban land spatial distribution through following the moving distance and direction of the center. The regional center of gravity model is derived using concepts from mechanics to express the coordinates $\left(X_{t}, Y_{t}\right)$ of the regional gravity center (Eq. 2; Wang et al., 2013).

$$
X_{t}=\sum_{i=1}^{n}\left(C_{t i} \times X_{i}\right) / \sum_{i=1}^{n} C_{t i} ; Y_{t}=\sum_{i=1}^{n}\left(C_{t i} \times Y_{i}\right) / \sum_{i=1}^{n} C_{t i} .
$$

Where, $X_{t}$ and $Y_{t}$ indicate the longitude and latitude of the gravity center in the study year $t$, respectively; $X_{i}$ and $Y_{i}$ indicate the geometric centers of land use type $i$, respectively; and $C_{t i}$ represents the area of land use type $i$ in the year $t$.

Gravity center movements include two aspects of distance and direction. The moving distance described how far the gravity center moved over a certain period while the moving direction indicates to which direction the urban expanded. The corresponding formula is as Equation 3. 


$$
D=\sqrt{\left(X_{1}-X_{2}\right)^{2}+\left(Y_{1}-Y_{2}\right)^{2}} .
$$

Where, $D$ is the distance moved; $X_{1}$ and $Y_{1}$ are the initial coordinates; and $X_{2}$ and $Y_{2}$ are the final coordinates of the urban gravity center.

\subsubsection{Urban expansion indices}

Urban expansion process can be quantitatively analyzed by the expansion speed and expansion intensity (Aimaiti et al., 2016). The expansion speed is the degree of expansion relative to the total urban land in preceding year (i.e., the year before the studied year), whereas the expansion intensity is the average annual growth rate of urban expansion during a particular study period. They can provide comprehensive assessments on the degree of urban expansion in terms of speed, area, ratio, and intensity.

Expansion speed (ES; Eq. 4; Kasimu et al., 2013) represents the degree of urban expansion of one specific study year in comparison with the degree of the preceding year. It was used to describe the overall changes in size and trends of the urban expansion.

$$
E S=\left[\left(\frac{L_{n+i}}{L_{n}}\right)^{\frac{1}{n}}-1\right] \times 100 \% .
$$

Where, $L_{n}$ and $L_{n+i}$ are urban areas in the years $n$ and $n+i$, respectively; and $n$ represents the length of the study period (Kasimu et al., 2013).

Expansion intensity (EI; Eq. 5) is the average annual growth rate of urban expansion over a period. It represents the annual average ratio of the increase in urban area to the initial total urban area.

$$
E I=\frac{U A_{n+i}-U A_{i}}{n U A_{i}} \times 100 \% .
$$

Where, $U A_{n+i}$ and $U A_{i}$ indicate the urban area in the years $n+i$ and $i$, respectively; $n$ is the length of the study period (Zhao and $\mathrm{Hu}, 2006$ ).

For Equations 2 and 3, the length of the study period $n$ was equal to 5 years for each of the five study periods (1990-1995, 1995-2000, 2000-2005, 2005-2010, and 2010-2015), and was equal to 25 years for the total study period 1990-2015.

3.3.4 Urban spatial pattern indices

The compactness and fractal dimensions are widely used to quantitatively evaluate the urban spatial patterns (Nie et al., 2015) and these indices can reveal the spatial shape, stability, and complexity of city boundaries. Compactness (Eq. 6) is an indicator reflecting the shape of a city. It provides a characterization of the basic features of an urban space and land use efficiency. Its value falls in the range of $0-1$ and the higher the value is, the higher the compactness of an urban will be. Low values indicate loose urban patterns. A circle is the most compact graphical form and the compactness of a circle is equal to 1 .

$$
C=\frac{2 \sqrt{\pi A}}{P}
$$

Where, $C$ is the compactness; $A$ is the area $\left(\mathrm{m}^{2}\right)$; and $P$ is the perimeter $(\mathrm{m})$ of the urban land (Kasimu et al., 2013).

Fractal dimension value (Eq. 7) is often used to indicate the degree of complexity and stability of city boundaries. Based on calculated values of the fractal dimension, the morphological characteristics of a city's spatial expansion during different periods can be inferred.

$$
D=\frac{2 \ln (0.25 P)}{\ln (A)} \text {. }
$$

Where, $D$ is the fractal dimension; $A$ is the area $\left(\mathrm{m}^{2}\right)$; and $P$ is the perimeter $(\mathrm{m})$ of the urban land (Kasimu et al., 2013). In general, the value of the fractal dimension is in the range of 1-2. The larger the value is, the more complex the city boundary is. If the value is less than 1.5 , the shape 
of the city tends to be simple. If the value is more than 1.5 , the city is in a state corresponding to Brownian random motion, and the shape of the city tends to be complex (Tu et al., 2013).

\section{Results and discussion}

\subsection{Land use types}

Based on the land use classification results, we produced land use classification maps for 6 different years (Figs. 2 and 3) using the ArcGIS 10.1 and calculated the relevant parameters. The areas occupied by urban land, farmland and unused land changed significantly over the whole study period. In particular, the urban land increased dramatically and mostly expanded to the southeastern direction. The unused land in the northern and southern parts of the city was fully utilized. The rapid increase in urban land well reflects the urban expansion trend.

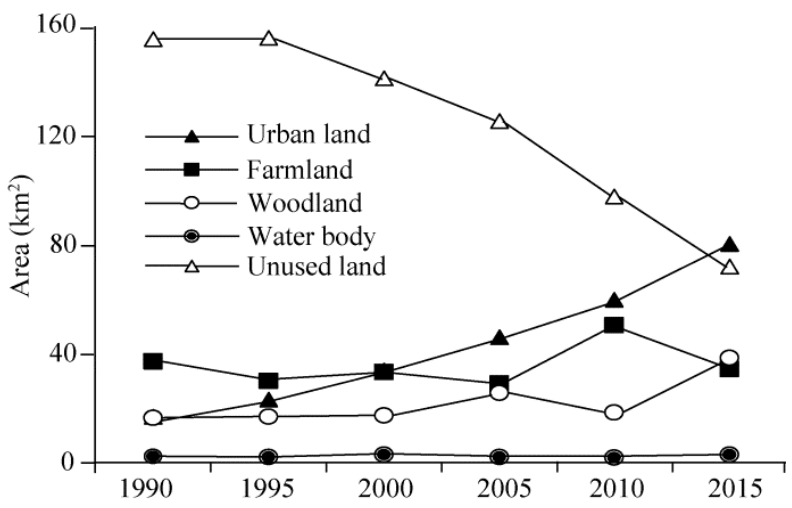

Fig. 2 Area changes of different land use types of Korla City during the period 1990-2015
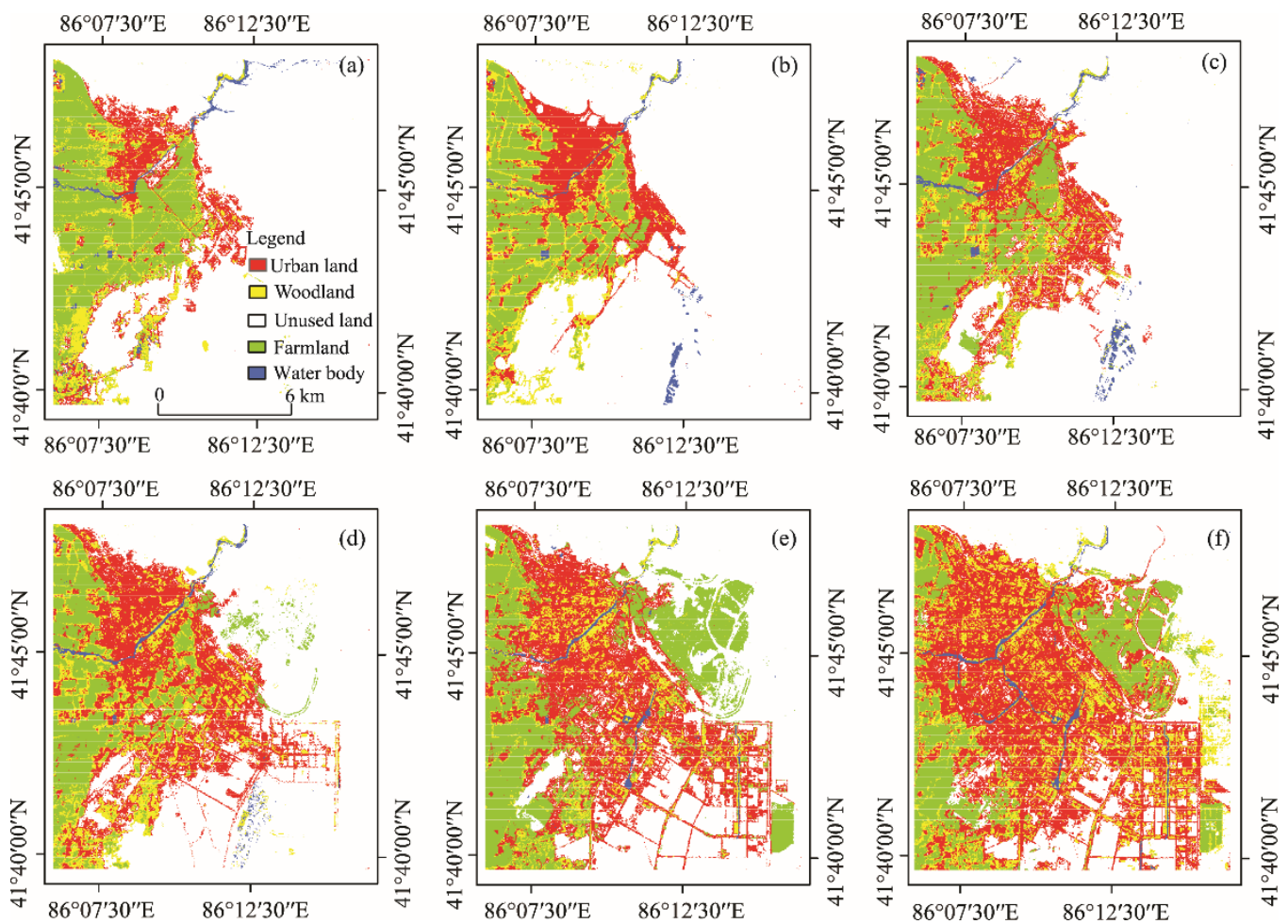

Fig. 3 Spatial distribution of different land use types of Korla City in 1990 (a), 1995 (b), 2000 (c), 2005 (d), 2010 (e), and 2015 (f) 
The urban area displayed a linear upward trend over the study period. It increased by $63.65 \mathrm{~km}^{2}$ from $16.77 \mathrm{~km}^{2}$ in 1990 to $80.42 \mathrm{~km}^{2}$ in 2015 with an annual expansion rate of about $15.18 \%$. The farmland area was 37.05 and $34.37 \mathrm{~km}^{2}$ in 1990 and 2015, respectively. From 2005 onward, the farmland area increased gradually and mainly concentrated in the northwestern city, and reached the peak in 2010 and then dropped. The woodland area presented a stable increasing trend since 2000 and reached $38.56 \mathrm{~km}^{2}$ in 2015 . The additional woodland was mainly concentrated in the central and southeastern city where the considerable urban expansion occurred. The water body areas include the Konqi River, Tarim River, and reservoirs in the southern city, which were relatively stable over the study period. The reduction in unused land was sharp and significant. During the early part of the study period, the unused land was mainly distributed in the northeastern, eastern, and southeastern city with an area of $155.69 \mathrm{~km}^{2}$ in 1990 . The unused land area was dropped to $72.01 \mathrm{~km}^{2}$ in 2015 and the annual decreasing rate was about $4.65 \%$.

\subsection{Urban land changes}

\subsubsection{Urban area expansion}

The urban area expanded significantly over the 25-year study period (Fig. 4). Using the urban land layer, the urban expansion maps were extracted by overlay analysis in ArcGIS 10.1 for the 6 periods (Fig. 5). The proportion of urban land expansion increased from $7.34 \%$ to $35.24 \%$. The urban land expansion presented an accelerated trend over the entire study period.

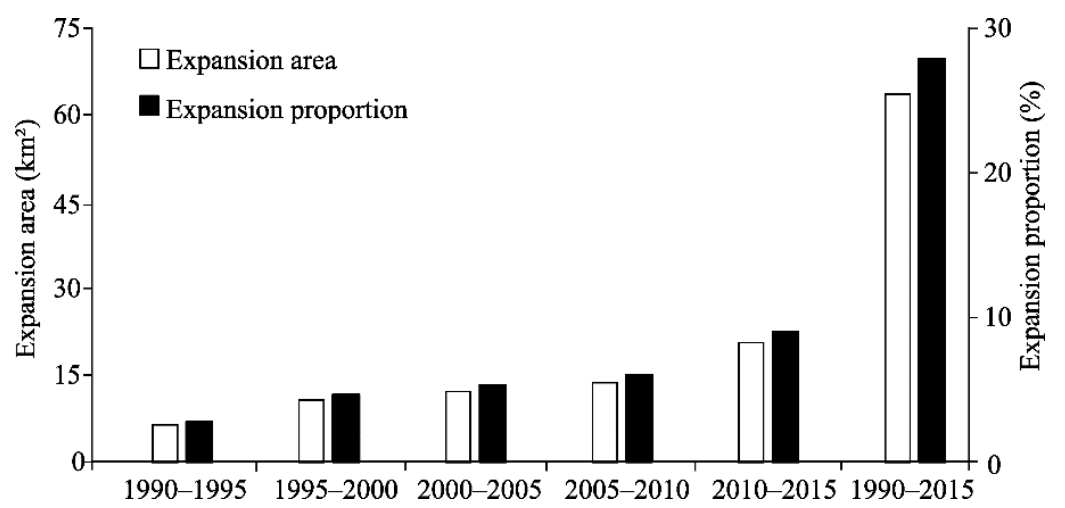

Fig. 4 Expansion area and proportion of urban land of Korla City in different study periods

\subsubsection{Urban land transfer matrix}

Figure 6 is the urban land transfer matrix maps for the 6 study periods and reflects the different land use types that were transferred to urban land type in each study periods. The total area for the entire period was not equal to the sum of the areas of the five sub-periods because the urban land was sometimes transferred back to the non-urban lands (Table 3).

Overall, the largest contributor to the urban expansion was the unused land and the second largest contributor was the farmland. In 1990, the area of unused land was about $155.69 \mathrm{~km}^{2}$, accounting for $27.82 \%$ of the total urban area of 2015. During the period $2010-2015,20.90 \mathrm{~km}^{2}$ of unused land were taken by the urban land, accounting for the largest increase among all of the study periods. In 1990, most of the central part of the city was farmland with an area of about $37.05 \mathrm{~km}^{2}$, in which about $18.62 \mathrm{~km}^{2}$ was transferred into urban land by 2015 .

\subsection{Changes of urban gravity center}

We calculated the coordinates and movements of the urban gravity centers for the study periods (Table 4). The movements of the center were presented in Figure 7. The urban gravity center moved towards northwest in 1990-1995 and moved towards the southeast continuously from 1995 to 2015. A small amount of unused land in the northeastern city was occupied by urban land. Since 1995, a large amount of unused land in the southern city was gradually taken by the urban land and the gravity center shifted towards the southeast accordingly. The gravity center moved $2118.46 \mathrm{~m}$ over the period 1990-2015. 

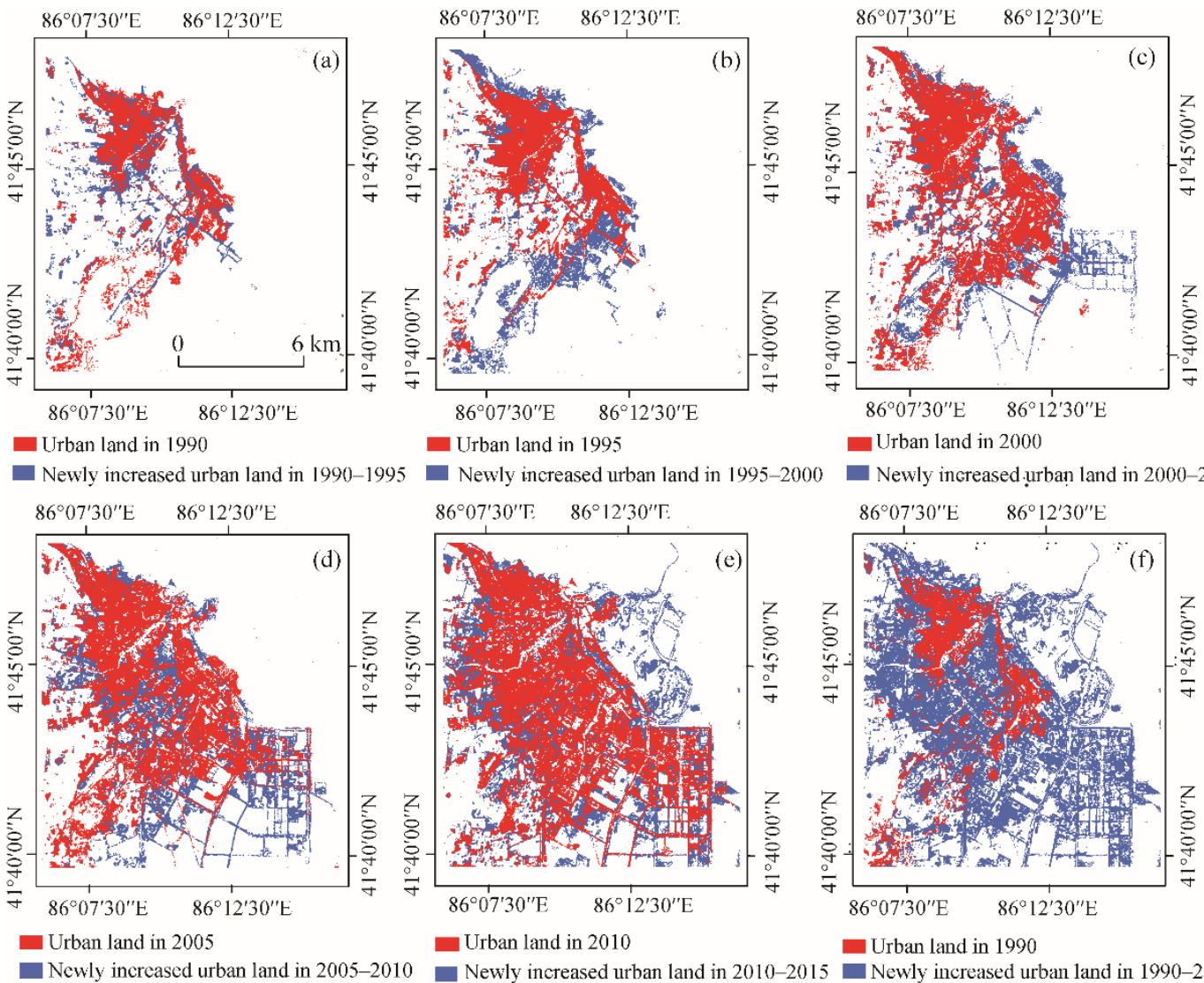

$86^{\circ} 07^{\prime} 30^{\prime \prime} \mathrm{F}: \quad 86^{\circ} 12^{\prime} 30^{\prime \prime} \mathrm{T}$ :

Newly increased urban land in 2000-2005
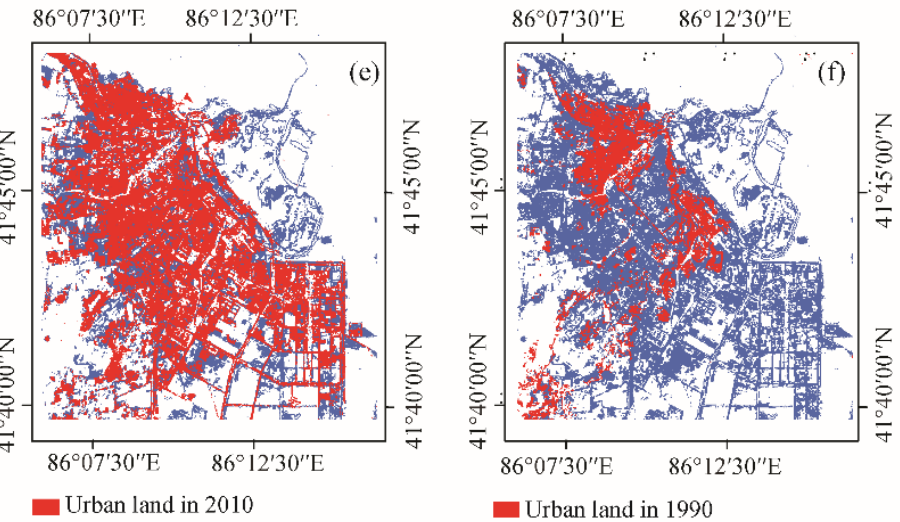

Fig. 5 Urban expansion of Korla City during the period 1990-2015

\subsection{Characteristics of urban expansion}

\subsubsection{Expansion speed and intensity}

According to the data extracted from ArcGIS 10.1, the expansion speed and the expansion intensity were calculated by Equations 4 and 5 using SPSS. The results were presented in Figure 8. Within each of the study periods, the expansion speed and expansion intensity were stable and the differences were not large; the values varied in the range of $6 \%-9 \%$. The maximum values of both the speed (8.27\%) and the intensity (9.35\%) appeared in 1990-1995.

\subsubsection{Urban spatial pattern changes}

The compactness and the fractal dimensions can be used to describe the urban spatial patterns. The maximum compactness value of 1.3625 and the minimum fractal dimension value of 0.040 occurred in 1995 and the city was relatively compact and stable with a simple shape. Both the compactness and the fractal dimensions presented obvious turning points in 1995 (Fig. 9). In 1990-1995, the newly added urban land converted from the unused land was mainly located in the northern city and on both sides of the Konqi River; the plots of unused land in the central city taken by the urban land were small in size and large in numbers. Therefore, the compactness and the fractal dimension of the city had no significant change although the urban land increased significantly. Since 1995, the land plots converted to urban land were disperse, the compactness dropped down to 0.0209 and the fractal dimension jumped up to 1.4321 in 2000 . Since then the compactness gradually decreased to 0.0156 and the fractal dimension gradually increased to 1.4432 in 2015 . The urban spatial pattern reached the most complex, unstable and loose stage over the entire study period.

\subsection{Driving forces of urban expansion}

\subsubsection{Geographical features}

Korla City is a typical oasis city in southern Xinjiang with dry climate and scarce water resources. 
The urbanization was restricted by both the topographic and climatic conditions. The city is bordered by the Horo Mountains to the north and by the Kuruktag Mountains to the east. The city is surrounded by salinized and desertified lands.
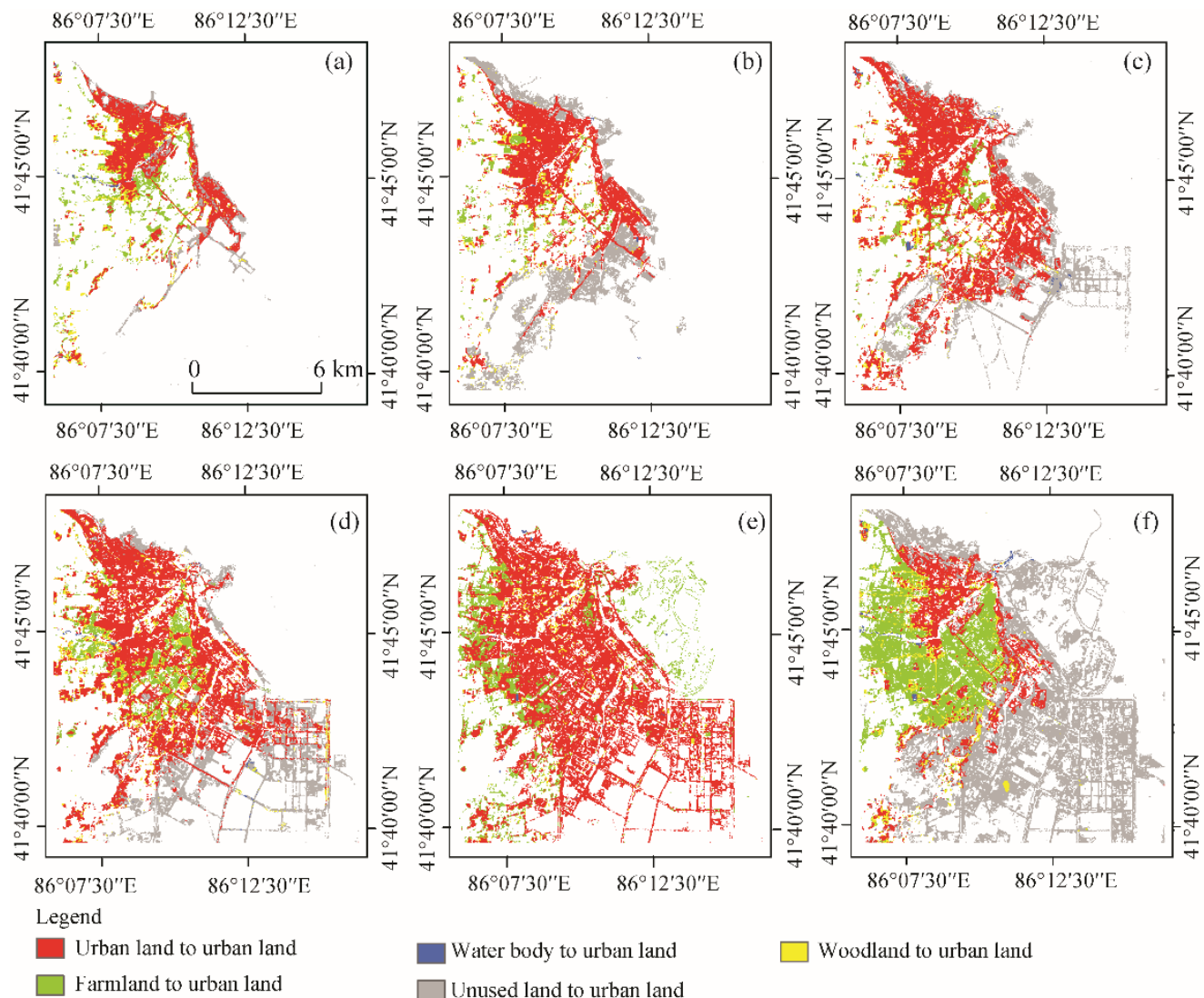

Woodland to urban land

Fig. 6 Urban land transfer matrix of Korla City in different periods. (a), 1990-1995; (b), 1995-2000; (c), 20002005; (d), 2005-2010; (e), 2010-2015; (f), 1990-2015.

Table 3 Land use types taken by urban land of Korla City during the period 1990-2015

\begin{tabular}{|c|c|c|c|c|}
\hline \multirow{2}{*}{ Study period } & Farmland & Woodland & Water body & Unused land \\
\hline & \multicolumn{4}{|c|}{$\left(\mathrm{km}^{2}\right)$} \\
\hline 1990-1995 & 3.61 & 3.62 & 0.29 & 4.75 \\
\hline 1995-2000 & 2.13 & 2.50 & 0.11 & 12.63 \\
\hline $2000-2005$ & 2.48 & 3.96 & 0.29 & 13.49 \\
\hline 2005-2010 & 4.46 & 7.64 & 0.28 & 16.27 \\
\hline 2010-2015 & 10.17 & 0.30 & 4.30 & 20.90 \\
\hline $1990-2015$ & 18.62 & 7.12 & 0.56 & 43.31 \\
\hline
\end{tabular}

Table 4 Movement of urban gravity center of Korla City

\begin{tabular}{|c|c|c|c|c|c|}
\hline \multirow{3}{*}{$\begin{array}{l}\text { Year } \\
1990\end{array}$} & \multirow{2}{*}{\multicolumn{2}{|c|}{ Coordinates }} & \multicolumn{3}{|c|}{ Movement } \\
\hline & & & \multirow{2}{*}{$\frac{\text { Period }}{1990-1995}$} & \multirow{2}{*}{$\frac{\text { Distance }(\mathrm{m})}{619.86}$} & \multirow{2}{*}{$\frac{\text { Direction }}{\mathrm{NW}}$} \\
\hline & $41^{\circ} 44^{\prime} 34^{\prime \prime} \mathrm{N}$ & $86^{\circ} 09^{\prime} 15^{\prime \prime} \mathrm{E}$ & & & \\
\hline 1995 & $41^{\circ} 44^{\prime} 53^{\prime \prime} \mathrm{N}$ & $86^{\circ} 09^{\prime} 10^{\prime \prime} \mathrm{E}$ & 1995-2000 & 896.55 & SE \\
\hline 2000 & $41^{\circ} 44^{\prime} 25^{\prime \prime} \mathrm{N}$ & $86^{\circ} 09^{\prime} 17^{\prime \prime} \mathrm{E}$ & 2000-2005 & 701.53 & SE \\
\hline 2005 & $41^{\circ} 44^{\prime} 10^{\prime \prime} \mathrm{N}$ & $86^{\circ} 09^{\prime} 39^{\prime \prime} \mathrm{E}$ & 2005-2010 & 899.31 & SE \\
\hline 2010 & $41^{\circ} 43^{\prime} 49^{\prime \prime} \mathrm{N}$ & $86^{\circ} 10^{\prime} 05^{\prime \prime} \mathrm{E}$ & 2010-2015 & 305.98 & SE \\
\hline 2015 & $41^{\circ} 43^{\prime} 42^{\prime \prime} \mathrm{N}$ & $86^{\circ} 10^{\prime} 15^{\prime \prime} \mathrm{E}$ & 1990-2015 & 2118.46 & SE \\
\hline
\end{tabular}




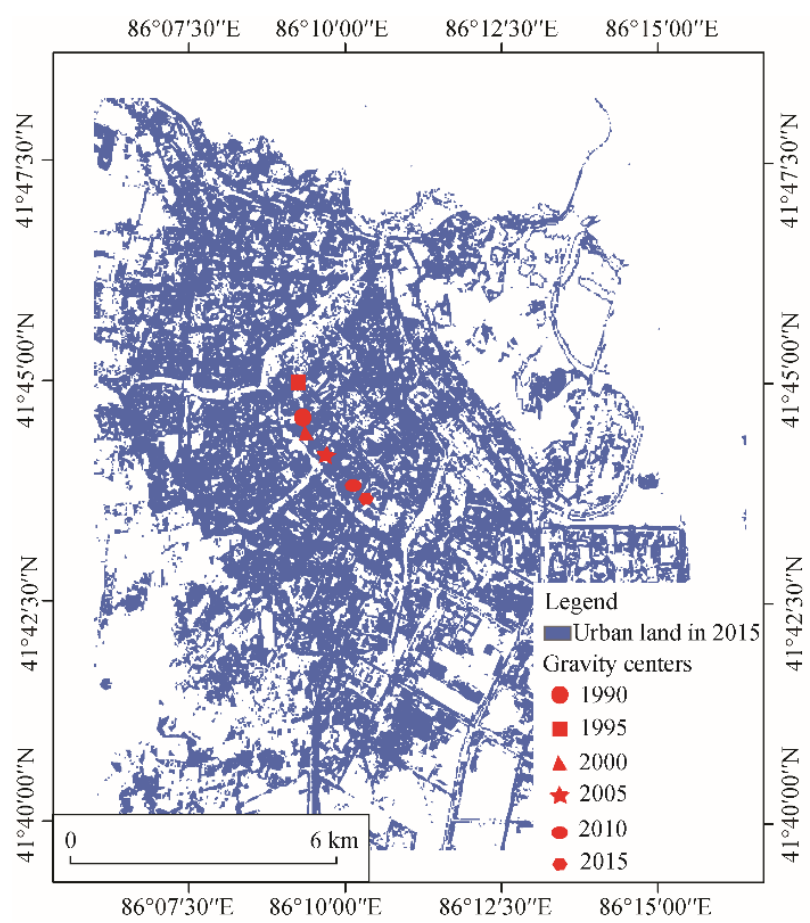

Fig. 7 Movement of the urban gravity center of Korla City during the period 1990-2015

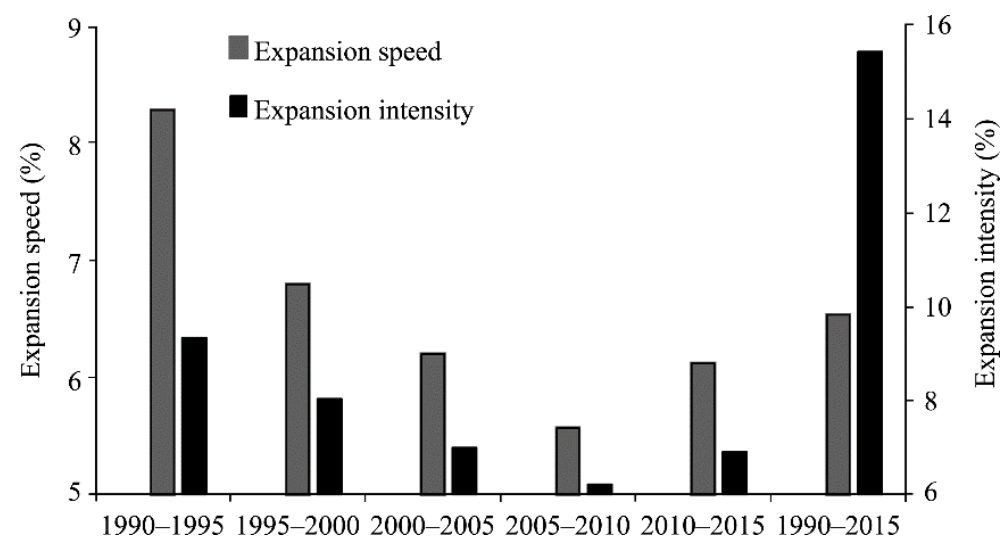

Fig. 8 Urban expansion speed and intensity of Korla City in six periods

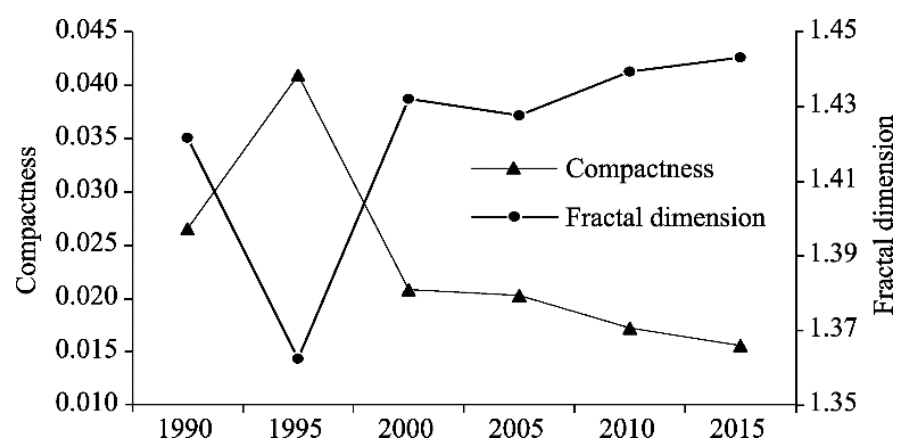

Fig. 9 Compactness and fractal dimension of Korla City during the period 1990-2015

\subsubsection{Population}

The rapid increased urban population was the most important factor driving the urban expansion. 
Over the 25-year study period, the population of the Korla City increased from $0.251 \times 10^{6}$ in 1990 to $0.559 \times 10^{6}$ in 2015 with an average annual growth rate of about $4.91 \%$. Dramatic population growth triggered high demands for residential, commercial and infrastructure (hospitals, sewage treatment plants and schools) lands. The correlation coefficient $\left(R^{2}\right)$ between the population and the urban land area was 0.9561 (Fig. 10), lending a strong support to our proposition that increased urban population was the most important factor driving the urban expansion.

\subsubsection{Rapid economic development}

The essence of urban expansion is a comprehensive process of economic development. With the exploration of the Tarim Oilfield in 1989 and the completion of the Natural Gas Transmission Project from West to East in 2007, the per capita GDP of Korla City increased substantially from $2.76 \times 10^{3}$ yuan in 1990 to $112 \times 10^{3}$ yuan in 2015 and the total GDP increased from $0.71 \times 10^{9}$ to $66.37 \times 10^{9}$ yuan (Fig. 11). At the same time, the output from tertiary industry was $0.24 \times 10^{9}$ yuan in 1995 and $12.97 \times 10^{9}$ yuan in 2015 . The correlation coefficient between the GDP and the urban land area was 0.9826 (Fig. 11), indicating that the economic expansion is another important factor driving the urban expansion.

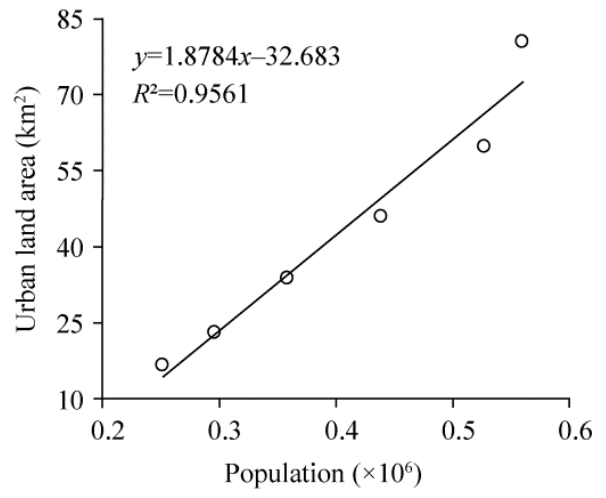

Fig. 10 Relationship between population and urban land area

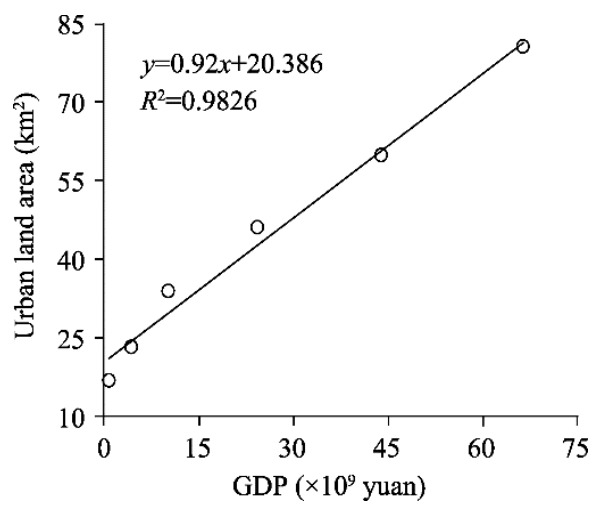

Fig. 11 Relationship between GDP and urban land area

\subsubsection{Government policies}

Administrative regulations play an important role in guiding the development of the city and also in restricting undesired urban expansion. Several significant events and strategies have promoted the development of Korla City and the corresponding urban expansion. These events and strategies include the Korla-Lopnur Integration Policy that started its enforcing stage in 2005, and the first and second Xinjiang Work Forums that took place in 2010 and 2014. The implementation of these policies, on one hand, accelerated Korla's economic development considerably. Specifically, from 1990 to 2015, the average annual growth rates of the regional GDP and the per capita GDP were $277.6 \%$ and $178.6 \%$, respectively. On the other hand, these factors triggered Korla City to expand at the cost of other land types, including farmland, woodland, water body, and unused land.

\subsubsection{Well-linked traffic lines}

Korla City is the most important transportation hub in southern Xinjiang. It links southern Xinjiang with northern and eastern Xinjiang. It is also well linked with many prefectures and cities in southern Xinjiang. Roads passing through Korla City include the Desert Highway to Hotan Prefecture, the National Highway 315 to Aksu Prefecture and Kashgar Prefecture, etc. Aviation is also highly developed here and the Korla Airport is the second-largest airport in Xinjiang. In particular, the operation of the Southern Xinjiang Railway Line in 1999 brought unprecedented development opportunities to Korla City. The well-linked traffic lines provided the necessary conditions for urban expansion. 


\section{Conclusions}

This study quantitatively analyzed the urban development process of Korla City using the widely-used indices to describe the spatial and temporal patterns of the urban expansion. Over the study period from 1990 to 2015 , due to the rapid development of the economy and the speedy growth of the population, the urban land increased greatly at the expenses of unused land and also other non-urban lands. The urban pattern was getting complex and unstable with the city compactness dropped and the fractal dimension increased. However, the rapid urbanization is often accompanied with social and environmental problems. With the rapid development of the core urban built-up area, the natural environment along the Konqi River was deteriorated. In addition, the newly expanded area in the southern city is very far from the city center, and the farther distances also created problems for city management. This study is a preliminary investigation of the expansion for a typical oasis city in the arid and semi-arid lands. Future research should employ images with higher spatial resolution than those of Landsat TM/ETM+ to elevate our understanding of the oasis city dynamics.

\section{Acknowledgements}

This study was funded by the National Natural Science Foundation of China (41161063, 41261090, 41361043, 41661036), the National Natural Science Foundation of China-Xinjiang Mutual Funds (U1603241), the Xinjiang Uygur Autonomous Region Science and Technology Support Project (201591101), the special fund of the Xinjiang Uygur Autonomous Region Key Laboratory (2014KL005, 2016D03001), and the Open Project Fund of the Key Laboratory of Oasis Ecology of the Education Ministry, Xinjiang University (040079).

\section{References}

Aimaiti Y, Kasimu A, Guo J. 2016. Urban landscape extraction and analysis based on optical and microwave ALOS satellite data. Earth Science Informatics, 9(4): 425-435.

Aithal B H, Ramachandra T V. 2016. Visualization of urban growth pattern in Chennai using geoinformatics and spatial metrics. Journal of the Indian Society of Remote Sensing, 44(4): 617-633.

Batty M, Xie Y. 1994. From cells to cities. Environment and Planning B, 21(7): 31-48.

Boori M S, Netzband M, Choudhary K, et al. 2015. Monitoring and modeling of urban sprawl through remote sensing and GIS in Kuala Lumpur, Malaysia. Ecological Processes, 4(1): 15.

Chen X, Yan J F, Chen Z, et al. 2009. A spatial geostatistical analysis of impact of land use development on groundwater resources in the Sangong oasis region using remote sensing imagery and data. Journal of Arid Land, 1(1): 1-8.

Collins J B, Woodcoch C E. 1996. An assessment of several linear change detection techniques for mapping forest mortality using multitemporal Landsat TM data. Remote Sensing of Environment, 56(1): 66-77.

Debbage N, Bereitschaft B, Shepherd J M. 2016. Quantifying the spatiotemporal trends of urban sprawl among large U.S. metropolitan areas via spatial metrics. Applied Spatial Analysis and Policy, 1-29, doi: 10.1007/s12061-016-9190-6.

Frankhauser P. 1990. Fractals aspects in urban structures. Espace Géographique, 19(1): 45-69. (in French)

Hagen-Zanker A, Timmermans H. 2008. A metric of compactness of urban change illustrated to 22 European countries. In: Bernard L, Friis-Christensen A, Pundt H. The European Information Society. Berlin Heidelberg: Springer, 181-200.

Kasimu A, Aimaiti Y. 2012. Study on spatial structure of urban greenbelt landscapes in Urumqi city based on ALOS satellite image. Areal Research and Development, 31(2): 86-89. (in Chinese)

Kasimu A, Maimaitiming A. 2012. A global comparative analysis of urban spatio-temporal variation during last four decades by using coarse resolution remote sensing data and GIS. Journal of Glaciology and Geocryology, 34(1): 214-220. (in Chinese)

Kasimu A, Tang B, Tulake G. 2013. Analysis of the spatial-temporal dynamic changes of urban expansion in oasis of Xinjiang based on RS and GIS. Journal of Glaciology and Geocryology, 35(4): 1056-1064. (in Chinese)

Li L, Chi Y B, Wang Z Y, et al. 2009. The spatio-temporal dynamic characteristics in expansion of major cities in China in 30 years since the Reform and Opening-up. Journal of Natural Resources, 24(11): 1933-1943. (in Chinese)

Liu F, Zhang Z X, Shi L F, et al. 2016. Urban expansion in China and its spatial-temporal differences over the past four decades. Journal of Geographical Sciences, 26(10): 1477-1496.

Liu J Y. 1997. Study on national resources \& environment survey and dynamic monitoring using remote sensing. Journal of Remote Sensing, 1(3): 225-230.

Liu J Y, Zhang Q, Hu Y F. 2012. Regional differences of China's urban expansion from late $20^{\text {th }}$ to early $21^{\text {st }}$ Century based on remote sensing information. Chinese Geographical Science, 22(1): 1-14. 
Liu S H, Sylvia P, Li X B. 2002. Spatial patterns of urban land use growth in Beijing. Journal of Geographical Sciences, 12(3): 266-274.

Liu W C, Liu J Y, Kuang W H, et al. 2017. Examining the influence of the implementation of Major Function-oriented Zones on built-up area expansion in China. Journal of Geographical Sciences, 27(6): 643-660.

Long Y, Han H Y, Mao Q Z. 2009. Establishing urban growth boundaries using constrained CA. Acta Geographica Sinica, 64(8): 999-1008. (in Chinese)

Luck M, Wu J G. 2002. A gradient analysis of urban landscape pattern: a case study from the Phoenix metropolitan region, Arizona, USA. Landscape Ecology, 17(4): 327-339.

Mohammady S, Delavar M R. 2016. Urban sprawl assessment and modeling using Landsat images and GIS. Modeling Earth Systems and Environment, 2(3): 155.

Ministry of Housing and Urban-Rural Development of the People's Republic of China (MOHURD). 1999. GB/T 50280-1998 Standard for basic terminology of urban planning. Beijing: China Standard Press. (in Chinese)

NBSC (National Bureau of Statistics of China). 2016. Statistical bulletin of National economic and social development in 2015. [2016-02-29]. Beijing: NBSC. http://www.stats.gov.cn/tjsj/zxfb/201602/t20160229_1323991.html. (in Chinese)

Nian Y Y, Li X, Zhou J, et al. 2014. Impact of land use change on water resource allocation in the middle reaches of the Heihe River Basin in northwestern China. Journal of Arid Land, 6(3): 273-286.

Nie Q, Xu J H, Liu Z H. 2015. Fractal and multifractal characteristic of spatial pattern of urban impervious surfaces. Earth Science Informatics, 8(2): 381-392.

Qiao W F, Mao G X, Wang Y H, et al. 2016. Research on urban expansion and land use change in Nanjing over the past 32 years. Journal of Geo-information Science, 18(2): 200-209. (in Chinese)

Statistics Bureau of Xinjiang Uygur Autonomous Region. 1991-2016. Xinjiang Statistical Yearbook. Beijing: China Statistics Press. (in Chinese)

Shi L F, Liu F, Zhang Z X, et al. 2015. Monitoring urban expansion and morphology changes of Tangshan by using remote sensing. In: Bian F, Xie Y. Geo-Informatics in Resource Management and Sustainable Ecosystem. Communications in Computer and Information Science, 482. Berlin, Heidelberg: Springer, 625-634.

Shi L Y, Shao G F, Cui S H, et al. 2009. Urban three-dimensional expansion and its driving forces: a case study of Shanghai, China. Chinese Geographical Science, 19(4): 291-298.

Sun P J, Song W, Xiu C L, et al. 2013. Non-coordination in China's urbanization: assessment and affecting factors. Chinese Geographical Science, 23(6): 729-739.

Tan M H, Li X B, Lv C H. 2005. Urban land expansion and arable land loss of the major cities in China in the 1990s. Science in China, 48(9): 1492-1500.

Tu J J, Xiang X Y, Yang L. 2013. Urban spatial expansion and its impact on ecological service values of Chongqing City Proper in the last 30 years. High Technology Letters, 19(2): 162-169.

Vizzari M. 2011. Spatio-temporal analysis using urban-rural gradient modelling and landscape metrics. In: Murgante B, Gervasi O, Iglesias A, et al. Computational Science and Its Applications-ICCSA 2011. Lecture Notes in Computer Science. Berlin, Heidelberg: Springer, 6782: 103-118.

Wang Y, Chen Y N, Li Z. 2013. Evolvement characteristics of population and economic gravity centers in Tarim River Basin, Uygur Autonomous Region of Xinjiang, China. Chinese Geographical Science, 23(6): 765-772.

Weng Q. 2001. A remote sensing-GIS evaluation of urban expansion and its impact on surface temperature in the Zhujiang Delta, China. International Journal of Remote Sensing, 22(10): 1999-2014.

Xiao L, Tian G J. 2014. Study on spatial modes and driving mechanisms of Tianjin's urban expansion. Resources Science, 36(7): 1327-1335. (in Chinese)

Yang H, Xiong H G, Chen X G, et al. 2015. Identifying the influence of urbanization on soil organic matter content and $\mathrm{pH}$ from soil magnetic characteristics. Journal of Arid Land, 7(6): 820-830.

Yang J J, Zhou W, Qian Y. 2010. Discussion on the character and defined methods of urban growth boundary: A case study of the protection and control planning of ecological zone in Hangzhou. Huazhong Architecture, 28(1): 122-125. (in Chinese)

Yeh A G O, Li X. 1999. Economic development and agricultural land loss in the Pearl River Delta, China. Habitat International, 23(3): 373-390.

Yu X J, Ng C N. 2007. Spatial and temporal dynamics of urban sprawl along two urban-rural transects: A case study of Guangzhou, China. Landscape and Urban Planning, 79(1): 96-109.

Zhang L H, Xie Z K, Zhao R F, et al. 2012. The impact of land use change on soil organic carbon and labile organic carbon stocks in the Longzhong region of Loess Plateau. Journal of Arid Land, 4(3): 241-250.

Zhao S Q, Zhou D C, Zhu C, et al. 2015. Rates and patterns of urban expansion in China's 32 major cities over the past three decades. Landscape Ecology, 30(8): 1541-1559.

Zhao X, Hu Z L. 2006. Application of remote sensing to studying urban expansion: A case of Xuzhou City. Journal of Xuzhou Normal University (Natural Science Edition), 24(2): 67-70. (in Chinese) 